\title{
Determination of cytokine regulated glycan expression by using molecularly imprinted polymers targeting sialic acid
}

\author{
Yuecheng Zhang, Kushtrim Llapashtica, Sudhirkumar Shinde, Börje Sellergren, Zahra El-Schich, Anette \\ Gjörloff Wingren
}

Department of Biomedical Sciences, Faculty of Health and Society, Malmö University, Malmö 20506, Sweden.

Correspondence to: Dr. Anette Gjörloff Wingren, Department of Biomedical Sciences, Faculty of Health and Society, Malmö University, Malmö 20506, Sweden. E-mail: Anette.gjorloff-wingren@mau.se

\begin{abstract}
How to cite this article: Zhang Y, Llapashtica K, Shinde S, Sellergren B, El-Schich Z, Wingren AG. Determination of cytokine regulated glycan expression by using molecularly imprinted polymers targeting sialic acid. J Cancer Metastasis Treat 2019;5:56. http://dx.doi.org/10.20517/2394-4722.2018.112
\end{abstract}

Received: 31 Dec 2018 First Decision: 18 Mar 2019 Revised: 16 Apr 2019 Accepted: 28 May 2019 Published: 11 Jul 2019

Science Editor: Rafat Siddiqui Copy Editor: Cai-Hong Wang Production Editor: Jing Yu

\begin{abstract}
Cancer cells often have an increased amount of glycans, such as sialic acid (SA), on the cell surface, which normally play an important role in cell growth, proliferation and differentiation. In this study, SA expression is determined by fluorescent nanoprobes, molecularly imprinted polymers, SA-MIPs. The nanoprobes are synthesized with an imprinting approach to produce tailor-made fluorescent core-shell particles with high affinity for cell surface SA. Inflammation and cytokine production are well known tumor promoters, modulating the cellular microenvironment, including an aberrant cell surface glycan pattern. The recombinant cytokines IL-4, IL-6, IL-8 and a cocktail of cytokines collected from stimulated T leukemia Jurkat cells were used to induce in vitro inflammation in two cell lines, and thereafter analyzed with the use of SA-MIPs and flow cytometry. One of the cell lines showed a different binding pattern of SA-MIPs after treatment with recombinant cytokines and the cytokine cocktail. This study shows that SA-MIPs can be an important tool in the investigation of overexpressed glycans in the tumor microenvironment.
\end{abstract}

Keywords: Cancer, cytokine, glycans, molecularly imprinted polymers, sialic acid

\section{INTRODUCTION}

Abnormal cell growth can be initiated through inflammation ${ }^{[1]}$. Cancer cells are able to reshape the microenvironment by expression of tumor-promoting chemokines and cytokines ${ }^{[2,3]}$. Fast growing cancer

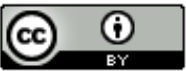

(C) The Author(s) 2019. Open Access This article is licensed under a Creative Commons Attribution 4.0 International License (https://creativecommons.org/licenses/by/4.0/), which permits unrestricted use, sharing, adaptation, distribution and reproduction in any medium or format, for any purpose, even commercially, as long as you give appropriate credit to the original author(s) and the source, provide a link to the Creative Commons license, and indicate if changes were made.

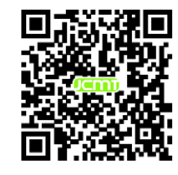


cells outpace their blood supply and become nutrient and oxygen deprived. This results in necrotic cell death at the tumor's core and this releases pro- inflammatory cytokines, such as IL-1.

Cytokines act as cell regulators of many different biological processes including cell growth, differentiation, metabolism, immunity and inflammation. Cytokines can enhance cancer cell growth by modulating the cellular microenvironment or by affecting the cells directly. Pro- inflammatory cytokines can be oncogenic and thereby inducing elevated levels of pro- invasive factors such as metalloproteinase-2 (MMP-2) and epithelial growth factor.

Pro-inflammatory cytokines including TNF- $\alpha$, IL-1 $\beta$, IL- 6 and IL- 8 are regulated by the transcription factor $\mathrm{NF}-\mathrm{kB}$, which is involved in activating genes in neoplastic transformation ${ }^{[1,4]}$. Highly glycosylated intestinal mucins, such as MUC2 and MUC4, are regulated through NF- KB and by the gp130/STAT3 pathways, respectively $y^{[5,6]}$.

Sialic acid (SA), or neuraminic acid, is the outermost sugar molecule of glycans, thus forming the outer surface of cells by being attached to proteins or lipids bound to the plasma membrane. SA is very important for the function of living organisms since it is involved in cell processes like proliferation, differentiation, angiogenesis, invasiveness and metastasis ${ }^{[7,8]}$. The over-expression of SA creates a negative charge on the cell surface, which is important in cell-cell and cell-matrix communication. An increased level of SA on the cell membrane, which have been reported on malignant and metastatic cancer cells, makes cells repel each other leading to an increased motility ${ }^{[9]}$. In addition, it has been proven that aberrant expression of in particular the $\alpha 2,3$-SA variants are related to tumor adhesion and invasion ${ }^{[1,11]}$.

Today, there is a lack of tools for specific targeting to glycans with high affinity. Lectins and glycan-specific antibodies have been used by many research groups to detect altered glycosylation, but the current tools do not perform with high specificity or affinity ${ }^{[12]}$. We have developed fluorescent nanoprobes to make convenient targeting and imaging of cell surface SA possible ${ }^{[13]}$. Based on other glycan specific receptors, we have developed SA-imprinted molecularly polymers (SA-MIPs) by using silica core particles and implemented NBD-fluorophores, which have favorable spectroscopic properties ${ }^{[13,14]}$.

In this study, two different cancer cell lines, MCF-7 and RAW 264.7, were stimulated with recombinant IL-4, IL-6, IL-8 and a cocktail of cytokines obtained by stimulating Jurkat T leukemia cells with phytohemagglutinine (PHA). The resulting expression of SA on the membrane of the stimulated cancer cells was analyzed with flow cytometry using both lectins and the SA-MIPs. One of the cell lines showed an increased binding of the SA-MIPs after treatment with recombinant cytokines and with the cytokine cocktail from PHA-stimulated Jurkat cells.

\section{METHODS}

\section{Cell culture}

The cell lines MCF-7 (ATCC HTB-22), RAW 264.7 (ATCCTIB-71) and Jurkat (ATCCTIB-152) were obtained from the American Type Culture Collection (ATCC/LGC Standards, Teddington, UK). MCF-7 and Jurkat cells were cultured in RPMI-1640 medium (Invitrogen, San Diego, CA, USA) supplemented with 10\% fetal bovine serum (FBS, Invitrogen) and $50 \mu \mathrm{g} / \mathrm{mL}$ gentamycin (Invitrogen) (complete medium). RAW 264.7 cells were cultured in RPMI-1640 medium supplemented with 10\% FBS and penicillin-streptomycin (Invitrogen). The cell lines were incubated in $37^{\circ} \mathrm{C}$ with $5 \% \mathrm{CO}_{2}$ in $100 \%$ humidity.

\section{Stimulation of Jurkat cells}

$5 \times 10^{6}$ Jurkat cells in $5 \mathrm{~mL}$ of were stimulated in complete medium with the addition of $10 \mathrm{ug} / \mathrm{mL}$ of PHA (Sigma Aldrich, St Louis, USA) for $72 \mathrm{~h}$. The cells were harvested and centrifuged at $300 \mathrm{xg}$ for $10 \mathrm{~min}$. The supernatant was kept at $4{ }^{\circ} \mathrm{C}$ until used for cell experiments. 


\section{Addition of recombinant cytokines}

$2 \times 10^{6}$ of each of MCF-7 and RAW 264.7 cells were seeded in T25 flasks. Next day, the medium was removed and the different recombinant cytokines IL-4, IL-6, IL-8 (Peprotech, Rocky Hill, NJ, USA), all added at a final concentration of $40 \mathrm{ng} / \mathrm{mL}$, or undiluted PHA- stimulated Jurkat supernatant was added to the cell culture flasks. One flask served as control with cells and medium alone. The cells were harvested after 3 days of incubation by trypsinization, two washes with phosphate buffered saline (PBS, Invitrogen) and thereafter stained with SA-MIPs according to below.

\section{Preparation of polymers}

The polymers (SA-MIPs) were prepared as described previously by Shinde et $a l^{[13]}$. Before the SA-MIPs were used for cell-based experiments, the dried SA-MIPs were resuspended in PBS and sonicated for 8 min with a VWR sonicator. The stock solution of $1 \mathrm{mg} / \mathrm{mL}$ was further sonicated and diluted in PBS prior to use.

\section{Flow cytometry analysis}

SA-MIPS

$1 \times 10^{6}$ cells/sample were stained with SA-MIPs or left unstained as a control. The cells were washed twice with $2 \mathrm{~mL}$ PBS and thereafter $100 \mu \mathrm{L}$ of SA-MIPs with indicated concentration was added to the cells. $100 \mu \mathrm{L}$ of PBS was used as a negative control. The cells were incubated with SA-MIP for $30 \mathrm{~min}$ at $4{ }^{\circ} \mathrm{C}$ in the dark, and were thereafter washed three times with $2 \mathrm{~mL}$ PBS and analyzed using flow cytometry (BD Biosciences, Accuri C6 Flow Cytometry, NJ).

\section{Lectins conjugated with biotin}

$1 \times 10^{6}$ cells/sample were stained with biotin-conjugated lectins (Vector Labs, Burlingame, CA, USA) or left unstained as a control. The cells were washed twice with $2 \mathrm{~mL}$ PBS. $100 \mu \mathrm{L}$ of biotin-conjugated lectins, MAL I (from Maackia amurensis) or SNA (from Sambucus nigra) at concentrations of $10 \mu \mathrm{g} / \mathrm{mL}$ was added to the cells and $100 \mu \mathrm{L}$ of PBS was used as a negative control. The cells were incubated with biotin- conjugated lectins for $30 \mathrm{~min}$ on $4{ }^{\circ} \mathrm{C}$ and were thereafter washed three times with $2 \mathrm{~mL}$ PBS. Thereafter $100 \mu \mathrm{L}$ of a 1:100 dilution of streptavidin-FITC (Agilent Technologies, Santa Clara, CA, USA) was added to the cells and incubated for $20 \mathrm{~min}$ at $4{ }^{\circ} \mathrm{C}$ in the dark. After the incubation, the cells were washed three times with $2 \mathrm{~mL}$ PBS and analyzed using flow cytometry (Accuri C6 Flow Cytometry).

\section{ELISAs for IL-2, IL-6, IL-8 and TNF- $a$}

96-well ELISA plates were coated overnight at room temperature with $100 \mu \mathrm{L} /$ well of diluted capture antibody against IL-2, IL-6, IL-8 or TNF- $\alpha$, respectively, according to the manufacturer's instructions (R\&D Systems, Minneapolis, MN, USA). The plates were washed three times with PBS-Tween (PBS-T), blocked by adding $300 \mu \mathrm{L} /$ well of blocking buffer (1\% BSA in PBS) and thereafter incubated at room temperature (RT) for $1 \mathrm{hr}$. After three washes with PBS-T, the plates were incubated with $100 \mu \mathrm{L} /$ well IL-2, IL-6, IL-8 or TNFstandards, respectively, diluted in reagent diluent, and $100 \mu \mathrm{L} /$ well of samples collected from the Jurkat cell supernatant. After an incubation of $2 \mathrm{~h}$ at RT, the plates were washed three times and thereafter $100 \mu \mathrm{L} / \mathrm{well}$ of $50 \mathrm{ng} / \mathrm{mL}$ biotin-linked detection antibody against IL-2, IL-6, IL-8 or TNF- $\alpha$, respectively, were added and incubated at RT for $2 \mathrm{~h}$. Then washed the plates three times and incubated with streptavidin-HRP at room temperature for $20 \mathrm{~min}$. After three washes with PBS-T, the plates were incubated with $100 \mu \mathrm{L} /$ well with substrate solution (1:1 mixture of $\mathrm{H}_{2} \mathrm{O}_{2}$ and tetramethylbenzidine, TMB) at $\mathrm{RT}$ for 20 min. After that, $100 \mu \mathrm{L} /$ well of stop solution was added and the plates were analyzed with a spectrophotometer at $450 \mathrm{~nm}$.

\section{Statistical methods}

Mean and standard deviation were used for statistical analysis of all calculations. 


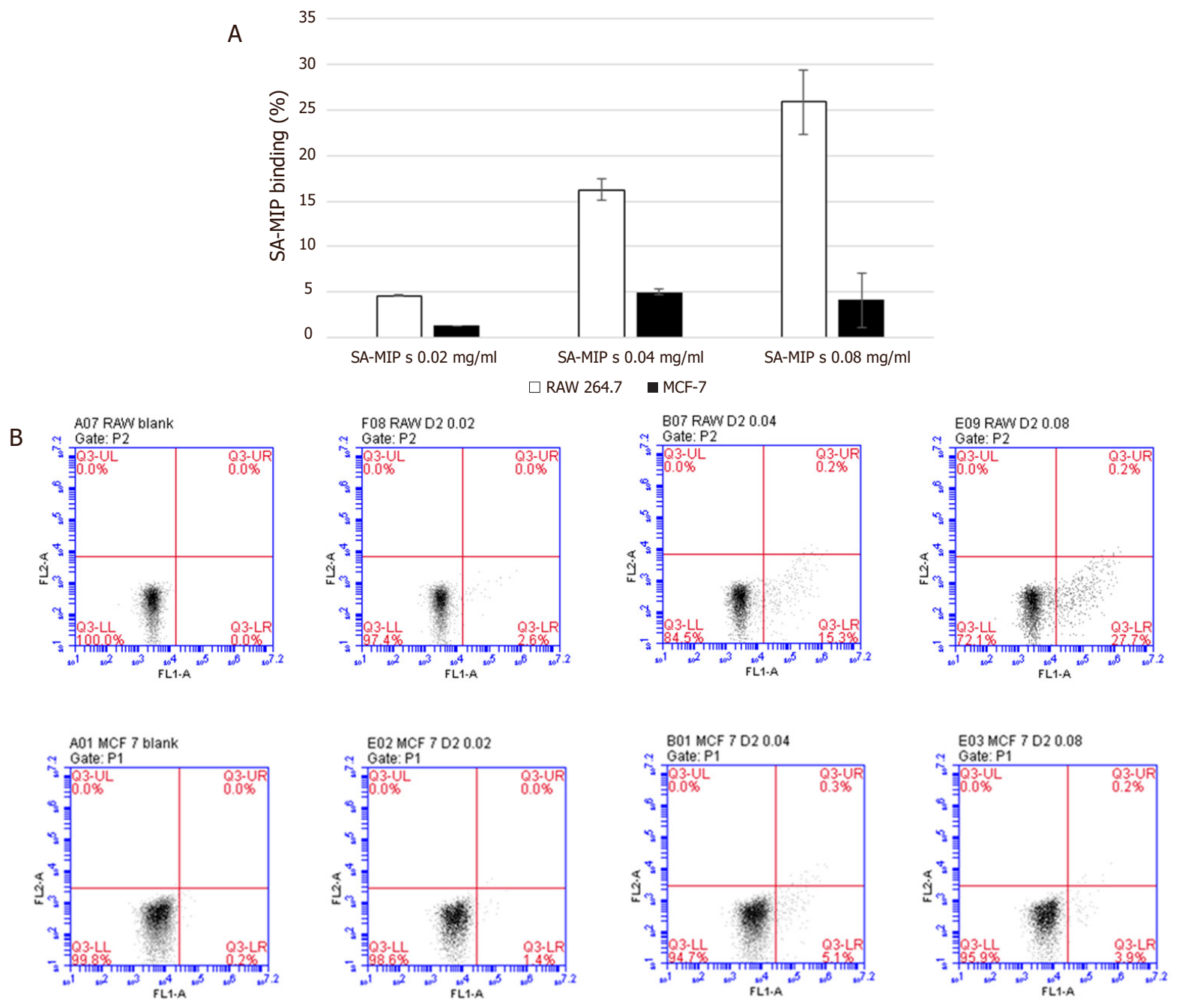

Figure 1. SA-MIP binding to RAW 264.7 cells and MCF-7 cells. A: Results of cells RAW 264.7 cells and MCF-7 cells stained with different concentrations of SA-MIP. B: Flow cytometry diagrams present the positive cells for SA-MIP concentrations $0.02,0.04$ and $0.08 \mathrm{mg} / \mathrm{mL}$, as dot-plot diagrams, respectively. The experiment shown in A represents the average of least three performed

\section{RESULTS}

\section{Evaluation of SA-MIP binding to MCF-7 and RAW 264.7 cells}

The breast cancer cell line MCF-7 and the macrophage cell line RAW 264.7 were tested for SA-MIP binding at different concentrations. Addition of increased concentration of SA-MIP resulted in higher SA-MIP binding [Figure 1A]. At the highest concentration of SA-MIPs used, $0,08 \mathrm{mg} / \mathrm{mL}$, the staining result was around $5 \%$ cell binding for MCF-7 cells and 65\% cell binding for RAW 264.7 cells. The dot-plot diagrams for RAW 264.7 cells (Upper figures) and MCF-7 cells (Lower figures) are shown in Figure 1B.

\section{SA-specific lectins show an increased binding to MCF-7 and RAW 264.7 cells after treatment with a cytokine cocktail}

First, the expression of SA on the cell lines were confirmed by using the lectins MAL I and SNA [Figure 2]. Then, the cells were treated with the cytokine cocktail from PHA-stimulated Jurkat cells, and a significant increased binding of the lectins could be detected in both cell lines [Figure 2].

\section{Cytokine treated MCF-7 and RAW 264.7 cells show a variation in SA-MIP binding}

Both cell lines were treated with the recombinant cytokines IL-4, IL-6 or IL-8. Alternatively, the cytokine cocktail from PHA-stimulated Jurkat cells was used. For the RAW 264.7 cells, treatment with IL-4 showed 


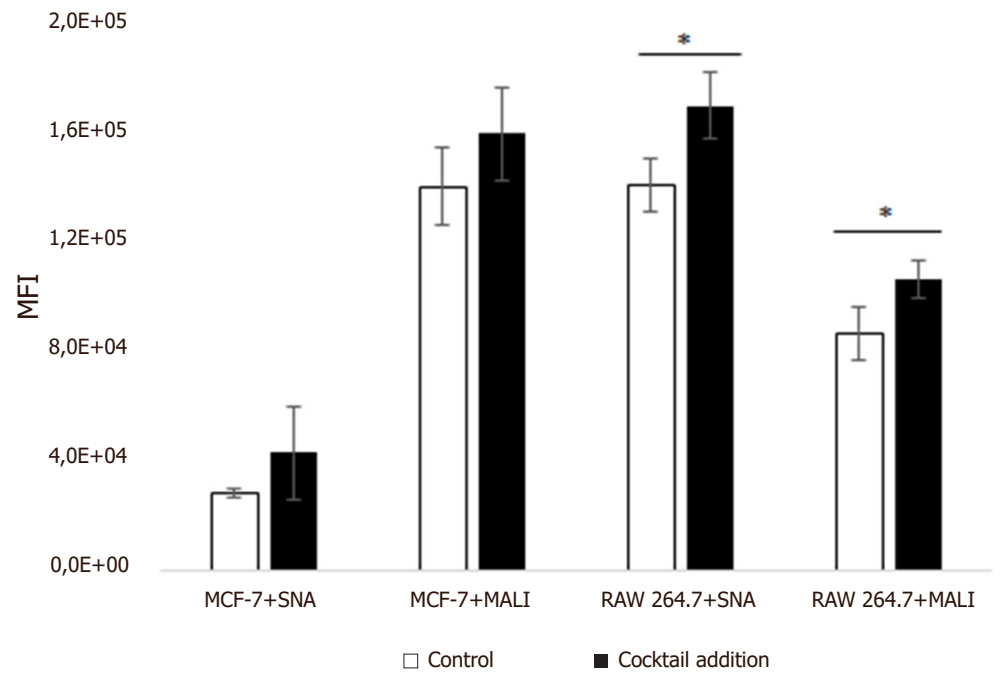

Figure 2. Lectin binding to RAW 264.7 cells and MCF-7 cells. Results of cells RAW 264.7 cells and MCF-7 cells stained with the MAL I and SNA lectins. Flow cytometry results present the mean fluorescence intensity for the lectins and a small increase in binding of the lectins after treatment with the cytokine cocktail. The experiment shown represents the average of least three performed

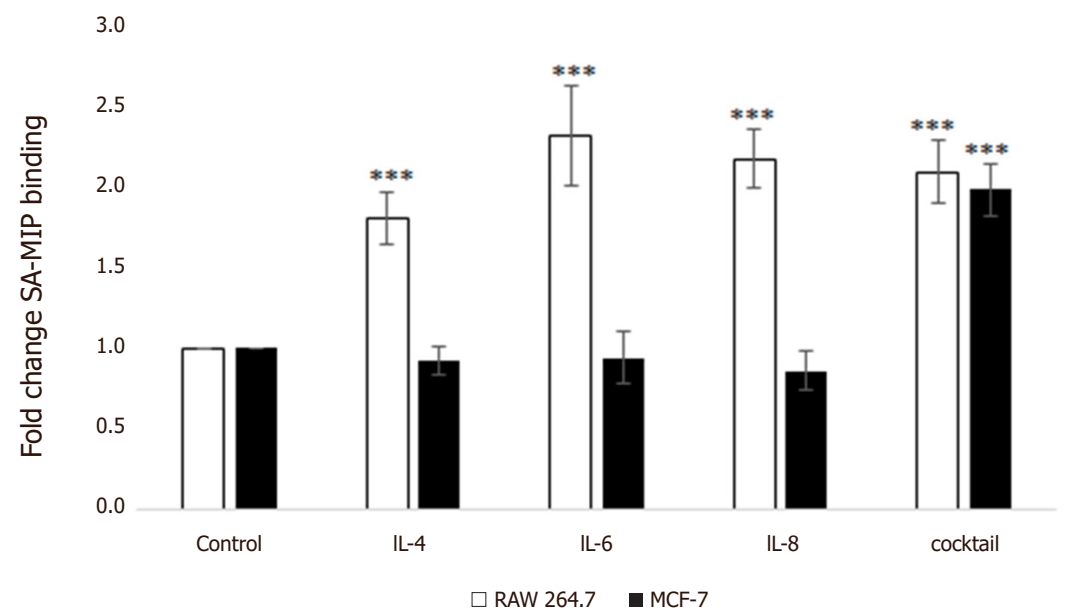

Figure 3. Flow cytometry of cytokine-treated RAW264.7 cells showing increase in SA-MIP binding after IL-4, IL-6, IL-8 or cocktail treatment. Results of cells RAW 264.7 cells and MCF-7 cells stained with SA-MIP. Flow cytometry results were re-calculated to fold change of response compared to control. The experiment shown represents the average of least three performed

an increase in SA-MIP binding in both cell lines, whereas IL-6 and IL-8 showed an even larger decrease [Figure 3]. The cytokine cocktail with unknown content influenced the SA-MIP binding in a similar manner as IL- 6 and IL-8. All additions of cytokines to RAW 264.7 cells were found to be significantly different from the control, as determined by statistical calculations.

For the MCF-7 cell line, addition of the recombinant cytokines IL-4, IL-6 or IL-8 did not influence any increase of SA-MIP binding to the cells [Figure 3]. No statistical significant difference could be determined for cytokine treatment of MCF-7 cells. However, addition of the cytokine cocktail induced a 2 -fold significant increase of SA-MIP binding in MCF-7 cells. To elucidate the cytokine content in the cocktail, ELISA was performed. 
Table 1. Cytokine content in PHA-stimulated Jurkat cells was analyzed with sandwich ELISAs detecting IL-2, II-6, IL-8 and TNF-, respectively

\begin{tabular}{|c|c|}
\hline Cytokines analyzed with ELISA in PHA-stimulated Jurkat cell sample & Cytokines detected $(\mathrm{pg} / \mathrm{mL})$ \\
\hline IL-2 negative control & 0 \\
\hline IL-2 stimulated sample & 17 \\
\hline IL-4 negative control & n.d. \\
\hline IL-4 stimulated sample & n.d. \\
\hline IL-6 negative control & 0 \\
\hline IL-6 stimulated sample & 0 \\
\hline IL-8 negative control & 0 \\
\hline IL-8 stimulated sample & 427 \\
\hline TNF-negative control & 0 \\
\hline TNF-stimulated sample & 12 \\
\hline
\end{tabular}

\section{PHA-stimulated Jurkat cells produce high amounts of IL-8}

The supernatants from stimulated and unstimulated Jurkat cells were investigated with sandwich ELISA specific for IL-2, IL-6, IL-8 and TNF- respectively [Table 1]. The levels of IL-2 and TNF- were low, but showed an increase compared to control. In contrast, more than $400 \mathrm{pg} / \mathrm{mL}$ of IL-8 was detected in the PHA-stimulated Jurkat cell supernatant. No IL-8 could be detected in the unstimulated control. IL- 6 could not detected in either stimulated or unstimulated samples.

\section{DISCUSSION}

In the tumor microenvironment, the cells of the immune system communicate with each other by releasing chemokines and cytokines to either favor antitumor immunity or enhance tumor progression. Thereby the cells control the immune and inflammatory milieu in a sophisticated fashion.

In this study we demonstrate that the SA-expression of RAW 264.7 and MCF-7 cells treated with recombinant cytokines in vitro could be analyzed with the use of SA-MIPs and flow cytometry. Interestingly, the cytokine-treated cells showed a modulated SA-MIPs binding pattern compared to the unstimulated controls. Stimulating macrophage RAW264.7 cells with IL-4, IL-6 or IL-8 cause an up-regulation of SA-MIP binding, while for the MCF-7 cells no increase could be determined. The effect of inflammatory cytokines on pancreatic cancer cells has been reviewed by Roshani $e t$ a $l^{[1]}$. In other studies, IL- 4 did not have any effect, but IL-6 and IL-8 were associated with poor prognosis and increased aggressiveness, respectively. IL-4 is an anti-inflammatory cytokine expected to down-regulate SA, while IL- 6 and IL-8 both up-regulate the SA expression. Indeed, IL-6 and IL-8 ${ }^{[15-1]]}$, as well as anti-inflammatory cytokines IL-10 and tumor growth factor-beta (TGF- $\beta)^{[1,18,19]}$ have been commonly shown to be elevated in pancreatic patients. Also, TNF- and IL- were upregulated compared to controls, but all studies in pancreatic cancer patients did not come to the same conclusions ${ }^{[1]}$. Other studies have proven that the levels of IL-4, IL- 6 and IL-8 in pancreatic cancer patients is higher than normal ${ }^{[15]}$. An important remark is that the pattern of cytokine expression varies between studies and even contradicting results have been obtained. Bassaganas et al.$^{[20]}$ studied pancreatic ductal adenocarcinoma cell lines treated with different cytokines. They found that treatment with either IL-1 or IL-6 resulted in an increased carbohydrate antigen and SA level. Also, the levels of mRNA of precursor of carbohydrate antigens was enhanced. Moreover, Dima et al ${ }^{[19]}$ found an association between higher levels of circulating TNF- $\alpha$ with poorer prognosis. These findings indicate that inflammatory cytokines can be pursued as potential prognostic biomarkers as well as therapeutic targets.

Escaping immune recognition is now a recognized hallmark of cancer ${ }^{[21]}$. Chemokines and cytokines can play a critical role in the immune evasion. Tumor cells can escape host immunity by producing immunosuppressive cytokines as well as by recruiting regulatory immune cells with immunosuppressive functions. 
The cellular expression pattern of glycosyltransferases and Lewis antigens detected in the normal mucosa can change during neoplastic transformation. The stomach mucosa was investigated for Lewis antigens in the presence of pro-inflammatory cytokines ${ }^{[4]}$. The level of one type of Lewis antigen decreased after treatment with IL-1 or IL-6, whereas the levels of other carbohydrate antigens were unaffected ${ }^{[4]}$.

Lectins are plant-derived macromolecules specific for carbohydrate moieties. The MAL lectin specifically bind the sialyl $\alpha 2,3 \mathrm{Gal} \beta 1,4 \mathrm{GlcNAc} / \mathrm{Glc}$ trisaccharide sequence ${ }^{[22]}$. Expression of $\alpha 2,3-\mathrm{SA}$ residues of $\mathrm{N}$-cadherin was shown to be altered in metastatic melanoma cell lines ${ }^{[23]}$. The expression of $\alpha 2,3-\mathrm{SA}$ residues in breast cancer using MAL-staining were analyzed by Cui et al. ${ }^{[24]}$ The results suggested that high levels of $\alpha 2,3$-SA residues was closely associated with lymph node metastasis and invasive depth in breast cancer patients. The highly metastatic breast cancer cell line MDA-MB-231 had higher expression of $\alpha 2,3$-sialic acid residues compared to T-47D and MCF-7 depending on the mRNA levels of $\alpha 2,3-\mathrm{ST}$ genes. Indeed, the tumor microenvironment can direct the level of inflammation. Also, the metastatic potential and malignancy of cancer cells is closely associated with aberrant sialylation pattern ${ }^{[24]}$.

The enzyme that adds $\alpha 2$-6linked sialic acids, $\beta$-galactoside $\alpha 2-6$ sialyltransferase (ST6Gal-I), is known to be upregulated in many tumor types including colon adenocarcinomas ${ }^{[25]}$, and high expression levels have been associated with poor prognosis and metastasis. ST6Gal-I sialylation of membrane glycoproteins contributes to metastasis by enhancing cell motility and invasion through the extra cellular matrix (ECM). Increased negative charged properties of sialic acids was correlated with reduced adhesiveness of tumor cells and may be suitable for conformational change of integrin and enhances its function in cell-ECM interactions ${ }^{[26]}$.

Interestingly, in our study we show a high expression of $\alpha 2,3-\mathrm{SA}$ on both cell lines, whereas the $\alpha 2,6-\mathrm{SA}$, as analyzed with the lectin SNA, displayed a lower expression on the MCF-7 cells. It has been shown that high levels of sialylation of cell surface glycoconjugates can significantly increase metastasis of colon carcinoma cells and human melanoma cells.

In addition to directly modulating cell motility, $\alpha 2,3$-SA residues are involved in the synthesis of sialyl Lewis $\mathrm{X}$ determinants, which are the major ligands for endothelial E-selectin ${ }^{[27]}$. The sialyl Lewis X structure on malignant cells is suggested to facilitate tumor cell dissemination by mediating the tumor-endothelial cell interactions ${ }^{[28,29]}$. Overall, many studies support the hypothesis that an increase of sialylation of cancer cells play an important role in tumor metastasis.

In the present study, the MCF-7 cell line showed a small increase of the SA-MIP binding after treatment with the cytokine cocktail derived from PHA-stimulated Jurkat cells. On the other hand, the SA-MIP binding when treating the RAW264.7 cell line with the same cocktail was not different compared to the effect of recombinant IL-6 or IL-8. Interestingly, an increase in binding of the lectins MAL and SNA was also detected after cytokine cocktail treatment. By analyzing with ELISA, we show that the cocktail contains increased amounts of IL-8, as well as low levels of IL-2 and TNF- $\alpha$. IL- 6 could not be detected in the PHA-stimulated samples. IL-8 is a chemokine, functioning by attracting cells to a site of infection, and it is therefore tempting to speculate that the increased SA-MIP binding seen by the RAW264.7 cells, could be due to a regulated SA-expression in response to IL-8. The natural ligands for SA are selectins and siglecs ${ }^{[30]}$. Indeed, the rolling of cancer cells ectopically expressing the selectin ligands on endothelial cells is potentially a crucial step favoring the metastatic process in $v i v{ }^{[3] 1}$. The combined analysis of SA and the targeting of SA to the ligands selectins and siglecs will be attractive for further investigations.

In conclusion, cancer cell migration and invasion is controlled by protein glycosylation and the ECM. SA is one of several important players in this crucial process. Inflammation and cytokine production will modulate the cellular microenvironment. We have studied cell lines in vitro that showed that one of the cell 
lines showed a significantly increased binding of the SA-MIPs after treatment with recombinant cytokines and with the cytokine cocktail from PHA-stimulated Jurkat cells. Here we demonstrate that SA-MIPs can be an important tool in the investigation of overexpressed glycans in the tumor microenvironment.

\section{DECLARATIONS}

\section{Authors' contributions}

Made substantial contributions to conception and design of the study and performed data analysis and interpretation: Zhang Y, Llapashtica K, Wingren AG

Performed data acquisition, as well as provided administrative, technical, and material support: El-Schich Z Provided administrative, technical, and material support: Shinde S, Sellergren B

\section{Availability of data and materials}

Not applicable.

\section{Financial support and sponsorship}

This work was supported by the European Union's Horizon 2020 research and innovation program under the Marie Sklodowska-Curie grant agreement (No 721297); the Knowledge foundation, Biofilms Research Center for Biointerfaces and Malmö University for financial support.

\section{Conflicts of interest}

All authors declared that there are no conflicts of interest.

\section{Ethical approval and consent to participate}

Not applicable.

\section{Consent for publication}

Not applicable.

\section{Copyright}

The Author(s) 2019.

\section{REFERENCES}

1. Roshani R, McCarthy F, Hagemann T. Inflammatory cytokines in human pancreatic cancer. Cancer Lett 2014;345:157-63.

2. Soucek L, Lawlor E, Soto D, Shchors K, Swigart LB, et al. Mast cells are required for angiogenesis and macroscopic expansion of Mycinduced pancreatic islet tumors. Nat Med 2007;13:1211-18.

3. Sparmann A, Bar-Sagi D. Ras-induced interleukin-8 expression plays a critical role in tumor growth and angiogenesis. Cancer Cell 2004;5:447-58.

4. Padro M, Mejias-Luque R, Cobler L, Garrido M, Perez-Garay M, et al. Regulation of glycosltransferases and Lewis antigens expression by IL-1B and IL-6 in human gastric cells. Glycoconj J 2011;28:99-110.

5. Mejias-Luque R, Linde, SK, Garrido M, Tye H, Najdovska M, et al. Inflammation modulates the expression of the intestinal mucins MUC2 and MUC4 in gastric tumors. Oncogene 2010;12:1753-62.

6. Mejias-Luque R, Peiro S, Vincent A, Van Seuningen I, deBolos C. IL-6 induces MUC4 expression through gp130/STAT3pathway in gastric cancer cell lines. Biochim. Biophys. Acta 2008;1783:1728-36.

7. Fuster MM, Esko JD. The sweet and sour of cancer: Glycans as novel therapeutic targets. Nat Rev Cancer 2005;5:526-42.

8. Varki, A. Sialic acids in human health and disease. (Invited Essay) Trends Mol. Med. 2008;14:351-60.

9. Dall'Olio, FC. Sialyltransferases in cancer. Glycoconjugate J 2001;18:841-50.

10. Czyzewska J, Guzińska-Ustymowicz K, Kemona A, Bandurski R. The expression of matrix metalloproteinase 9 and cathepsin B in gastric carcinoma is associated with lymph node metastasis, but not with postoperative survival. Folia Histochem Cytobiol 2008;46:5764.

11. Lin S, Kemmner W, Grigull Sand Schlag PM. Cell surface alpha 2,6 sialylation affects adhesion of breast carcinoma cells. Exp Cell Res 2002;276:101-10. 
12. Foster A, Brid R, Kelly S, Nishimura K, Poyner D, et al. FITC-Lectin avidity of Cryptocoous neoformans cell wall and capsular components. Mycologia 2004;96:1-8.

13. Shinde S, El-Schich Z, Malakpour A, Wan W, Dizeyi N, et al. Sialic acid-imprinted Fluorescent core-shell particles for selective labeling of cell surface glycans. JACS 2015;137:13908-12.

14. El-Schich Z, Abdullah M, Shinde S, Dizeyi N, Rosén A, et al. Different expression of glycans on leukemic cells - a screening with molecularly imprinted polymers targeting sialic acid. Tumor Biol 2016;37:13763-8.

15. Tucker SL, Ebrahimi B, Li D, Abbruzzes JL, Kurzrock R. Cytokines in pancreatic carcinoma: correlation with phenotypic characteristics and prognosis. Cancer 2004;101:2727-36.

16. Zhang Y, Li M, Feurino LW, Wang H, Fisher WE, et al. Interleukin-8 increases vascular endothelial growth factor and neuropilin expression and stimulates ERK activation in human pancreatic cancer. Cancer Sci 2008;99:733-7.

17. Miron M, Miron MM, Mile VG, Cristea V. Proinflammatory cytokines: an insight into pancreatic oncogenesis, Roum. Arch. Microbiol. Immunol 2010;69:183-9.

18. Smirne C, Bellone G, Mauri FA, Tonel E, Carbone A, et al. Cytokine expression profile in human pancreatic carcinoma cells and in surgical specimens: implications for survival, Cancer Immunol. Immunother 2006;55:684-98.

19. Dima SO, Tanase C, Albulescu R, Herlea V, Chivu-Economescu M, et al. An exploratory study of inflammatory cytokines as prognostic biomarkers in patients with ductal pancreatic adenocarcinoma. Pancreas 2012;41:1001-7.

20. Bassaganas S, Allende H, Cobler L, Ortiz MR, Llop E, et al. Inflammatory cytokines regulate the expression of glycosyltransferases involved in the biosynthesis of tumor- associated sialylated glycans in pancreatic cancer cell lines. Cytokine 2015;75:197- 206.

21. Hanahan D, Weinberg RA. Hallmarks of cancer: the next generation. Cell 2011;144:646-74.

22. Imberty A, Gautier C, Lescar J, Pérez S, Wyns Land Loris R. An unusual carbohydrate binding site revealed by the residues of two Maackia amurensis lectins complexed with sialic acid-containing oligosaccharides. J Biol Chem 2000;275:17541-8.

23. Ciolczyk-Wierzbicka D, Gil D, Hoja-Lukowicz D, Litynska A, Laidler P. Carbohydrate moieties of N-cadherin from human melanoma cell lines. Acta Biochim Pol 2002;49:991-9.

24. Cui H, Lin Y, Yue L, Zhao X, Liu, J. Differential expression of the $\alpha 2,3$-sialic acid residues in breast cancer is associated with metastatic potential. Oncol Rep 2011;25:1365-71.

25. Shaikh FM, Seales EC, Clem WC, Hennessy KM, Zhou Y, et al. Tumor cell migration and invasion are regulated by expression of variant integrin glycoforms. Exp Cell Res 2008;314:2941-50.

26. Seales EC, Jurado GA, Brunson BA, Wakefield JK, Frost AR, et al. Hypersialylation of beta1 integrins, observed in colon adenocarcinoma, may contribute to cancer progression by up-regulating cell motility. Cancer Res 2005;65:4645-6.

27. Kannagi R, Izawa M, Koike T, Miyazaki K, Kimura N. Carbohydrate-mediated cell adhesion in cancer metastasis and angiogenesis. Cancer Sci 2004;95:377-84.

28. Chen S, Fukuda M. Cell type-specific roles of carbohydrates in tumor metastasis. Methods Enzymol 2006;416:371-80.

29. Miyazaki K, Ohmori K, Izawa M, Koike T, Kumamoto K, et al. Loss of disialyl Lewis(a), the ligand for lymphocyte inhibitory receptor sialic acid-binding immunoglobulin-like lectin-7 (Siglec-7) associated with increased sialyl Lewis(a) expression on human colon cancers. Cancer Res 2004;64:4498-505.

30. Rodrigues E, Macauley MS. Hypersialylation in cancer: modulation of inflammation and therapeutic opportunities. Cancers (Basel) 2018;10:E207.

31. Trinchera M, Aronica A, Dall'Olio FC. Selectin ligands sialyl-Lewis a and sialyl- Lewis x in gastrointestinal cancers. Biology $2017 ; 6$ :E16. 